\begin{tabular}{|c|c|c|c|}
\hline PORT SAID ENGINEERING RESEARCH JOURNAL & Faculty of Engineering - Port Said University \\
\hline & No.2 & September 2020 & pp. 52-62 \\
\hline
\end{tabular}

\title{
A Hydrodynamic Study of Water Flushing Parameters to Improve the Water Quality inside Marinas and Lagoons
}

\author{
Elsayed M. Galal', Ahmed A. Lebleb ${ }^{2}$, Ehab R. Tolba ${ }^{3}$
}

Received: 12 February 2020; Accepted: 5 March 2020

\begin{abstract}
The flushing study is very important part to ensure the water quality and check the preliminary layout of the project to circulate and renewing the water body with adequate time. This research describes how to integrate engineering and environmental aspects into the planning with extensive use of numerical Hydrodynamics (HD) models by using MIKE 21 software. A parametric study of different parameters which affect the residence time hence the water quality in lagoons, marinas, harbors and coastal basins was carried out to establish guidelines for improvement methods of water flushing in marinas and lagoons. Finite element conceptual models are applied to simulate and investigate the most important factors dominate the resident time and water exchange rate such as tidal inlets characteristics (number-location-width), the shape of water body, basin dimensions and tidal variations. Data of water level variations used in simulations are collected based on the conditions of fishery ports and lagoons along Egyptian coastal line in both Mediterranean and Red sea. In this study, a wide range of numerical simulation (more than $50 \mathrm{HD}$ models) with different geometry boundary conditions were conducted. The results showed that the square shape of water surface area is more efficient in water circulation improvement for small water body areas. While, as the area required increased, the rectangular water surface efficiency in water circulation improvement become closer to the square shape with same surface area. The inlet width and its location should be determined wisely to achieve the optimization of its function. Finally, the results showed that as the values of the sea level variations increased the maximum flood current velocities at the entrance increased. In addition, the flow spreading efficiency increased with the higher water level values over the whole water surface regardless of the water depth.
\end{abstract}

KEYWORDS: Flushing; Residence time; Tidal current; Advection-Dispersion; Water Quality; Water Circulation; Hydrodynamic model; Tidal Prism.

\section{INTRODUCTION}

The continued growth of population in the world with increasing desire to live at the coast implies that the currently recreational and commercial coastal develoment, such as resorts, artificial islands, ports, marinas, and coastal lagoon, will not satisfy future demand which lead governments to put large investment on these kind of coastal projects. These kind of projects need environmental review and management planning wherein the importance of water quality assessment has become more essential than before. The water quality in a semi closed water body (port, marina, lagoon) is controlled by the rate and efficiency of water exchange between the water body and open sea water and the ability to flush out the trapped pollutants (Juhl and Gierlevsen [11]; Miller, et al., [14]).

The coastal projects and lagoon development should be subjected to environmental impact assessment to ensure that there is no harmful impact reflection on the environmental conditions of the development area. This assessment is carried out using accurate simulation by

\footnotetext{
${ }^{1}$ Associate Professor, Faculty of Engineering, Port Said University, Egypt, email: Elsayed.galal@eng.psu.edu.eg

${ }^{2}$ Coastal and Marine Eng., DAR Al-Handasah, Giza, Egypt, corresponding author, email:ahmed.lebleb@dar.com

${ }^{3}$ Professor, Faculty of Engineering, Port Said University, Egypt, Email: tolba_1966@yahoo.com

DOI: $\underline{10.21608 / \text { pserj.2020.23849.1032 }}$
}

collecting long term meteorological and environmental data beside the expected conditions of the planned development. Environmental impact assessment and coastal management studies using numerical models helps the coastal engineers to analyze and check the environmental and coastal problems to prevent the predictive hazards with a minimal amount of errors. The most useful advantage of numerical solution is the ability of changing the input parameters easily and observing the consequences to find the optimized solution (Simmons, et, al. [10]).

This study aims to define the parameters that affect the flushing process in semi-closed water body in order to enhance the water quality inside marinas and coastal lagoons. The flushing time should be optimized to achieve the efficient circulation of the water body considering the other parameters.

The most dominated Flushing parameters such as water surface area, basin geometry, tidal level variation, inlet characteristics, water depth, and approach channel are considered in this study.

There are two ways to simulate such conditions, by using physical and numerical models. The physical way models are much more expensive comparing with the numerical models (Blacka, et al., [13] and Pual, [14]). According to the continues development in software and computer 
technology, the using of numerical models become more preferable than before due to the high accuracy of result obtained with low cost and time comparing with physical models. Furthermore, numerical models help the coastal engineers to change the input parameters easily and observe the consequences to find the optimized solution (Simmons, et, al., [10]).

More than 50 different scenarios were numerically simulated using MIKE-21package, Developed by the Danish Hydraulic Institute DHI, (Klein, [12]). The boundary conditions and input data used in simulation were carefully collected to match with the conditions of the coastal zone of Mediterranean Sea and Red Sea along Egyptian coasts-

The study will set guidelines for planning of a semi closed water body like marina, port, and man-mad island that optimize the residence time to improve water quality. These guidelines will also include lagoons development strategies.

\subsection{Flushing Definition}

In basic sense and simple way, flushing is a physical exchange in a specific volume of water between one water body and another, typically regarded as the connected water body, existing or surrounding water. The fluid medium carries the mix of dissolved gases, nutrients, organisms, and suspended material comprising the aquatic environment. The hydrodynamic processes which transport the water and its constituents is considered the key to understand the flushing system (Dyke, [6]).

It is often difficult to measure the flushing time, time needed to renew water inside a semi closed water body by feeding new water from connecting sea. Therefore, it should be estimated by appropriate models (Kusnierz, et al., [17]; Ranasinghe and Pattiaratchi, [18]).

The most common way to assess the flushing is to model the numerical tracer in the interest area. This tracer is introduced in the model after the initial spin-up period and cover area of the study. The tracer is being dispersed with current induced by water level variation. The time it takes to disperse the tracer to a certain percentage of the initial (100\%) concentration is defined as the flushing/ residence time of the area. (Goshow, et al., [9]).

For example, Thomann and Mueller, [20], in the wellknown form, write the change in concentration (mass / volume) with time:

$$
C_{t}=C_{0}\left\{e^{\left(\frac{-Q t}{v}\right)}\right\}=C_{0}\left\{e^{\left(\frac{-t}{T_{f}}\right)}\right\}
$$

Where $C_{o}$ is the initial concentration, $C_{t}$ is the concentration at specific time $t$. $Q$ is the continuing flow rate, $\mathrm{v}$ is the water volume and $T_{f}$ is flushing/residence time (Nece, and Richey, [16]).

Water inside a semi-closed body is refreshed by three processes advection, dispersion and diffusion. Advection is the process of horizontal movement of flow when the water level rises in the area around the water body due to tidal variation. Dispersion is induced by differences in current velocities vertically, but it is not a dominated parameter in flushing processing and that can be understood clearly when comparing the $2 \mathrm{D}$ model results with results of $3 \mathrm{D}$ model. Diffusion is a process that accounts for the spreading (and hence dilution) of a substance in water, from an area of high concentration to an area of low concentration. The process of diffusion could be less significant compared to the process of advection, when the flows are sufficiently strong, since the time-scale of diffusion is usually longer. In weaker flow conditions, the contribution due to diffusion could be more substantial. (Nece, and Richey, [16]).

\subsection{Flushing-Historical Review}

Flushing time has historically been used in coastal environmental assessment in order to predict the potential water quality in marinas, ports, and coastal lagoons. The previous and ongoing research have presented guidance in relation to optimize basin geometry (e.g. tidal prism ratio, plan form factor, aspect ratio, relative entrance area, curvature) in order to achieve rapid renewal. However, there are plenty number of publications of water flushing study, most of them have been developed for a case study. The water circulation, between a semi-closed water body and the open sea, is generally produced by surrounding natural conditions such as the local tidal range, wave climate, water density, geographical location, and meteorological condition. In additional to the natural condition. The planning of basin geometry is also affect the water exchange rate such as basin length to width ratio and inlet characteristics (dimension, width, and numbers). Therefore, once those parameters are understood, coastal development can be planned to have an optimal water exchange (Nece, [15]).

\section{MODEL SETUP}

In this study, a numerical model was used in order to simulate the water flow inside a semi closed water body for different scenarios and cases. More than 50 hydrodynamic runs were done using MIKE-21 FM software to cover all possible scenarios to assess the effect of studied parameters on flushing system (DHI, [3, 4]).

The models' simulation was done using a finite element flexible mesh with finer discretization towards the simulated semi-closed water body as shown in Figure 1. The mesh is finer at basin inlet(s) and inside basin itself and become coarser further away from inlet(s). The mesh size varied from $5 \mathrm{~m}$ to $250 \mathrm{~m}$.

The purpose of simulation is to produce HD model that can be used to investigate the hydrodynamics inside the water body. The simulation is planned to run for a period long enough to flush at least $80 \%$ of the semi-closed water body.

The boundary conditions applied in simulation were defined based on the collected data for the conditions of fishery ports and lagoons along the Egyptian coasts of both the Mediterranean and Red sea. All coastal Lagoons in Egypt are only located along Mediterranean Sea, as shown in Figure 2. They are (from East to West) Bardawil Lagoon, Manzala Lagoon, Burullus Lagoon, Edku Lagoons and Maryut Lagoon (Sharaan, et al., [19]). There are many fishery ports in Egypt which are considered the main source of fish in the country. Those ports are 
distributed along the Egyptian coasts of both Mediterranean and Red Sea as shown in Figure 3. Four of them are along Red sea: Attake, Salakhana, Hurghada, and El-Tor, while the other four are along Mediterranean Sea: Port Said, Ezbat Al-Borg, New El-Burullus, and Elmaadiya (Sharaan, et al., [19]).

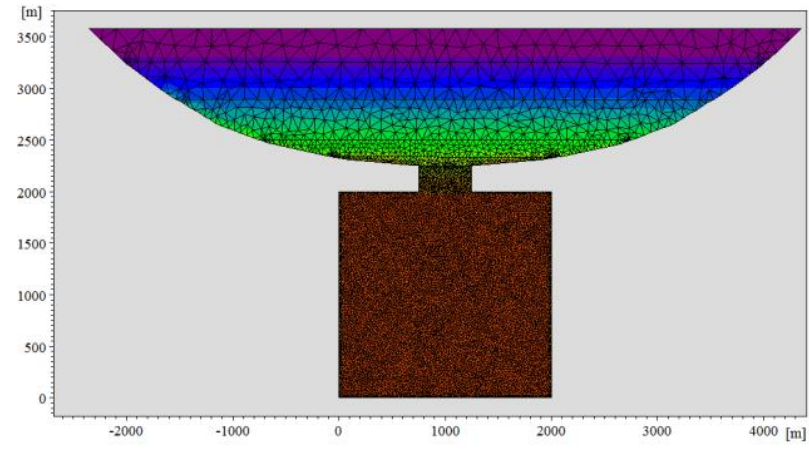

Figure 1: Model finite element network and mesh element size

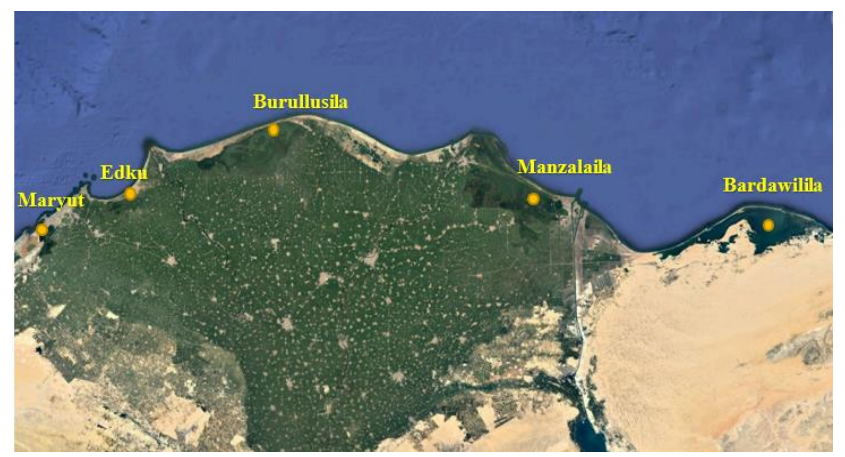

Figure 2: Coastal lagoons along Egyptian coasts

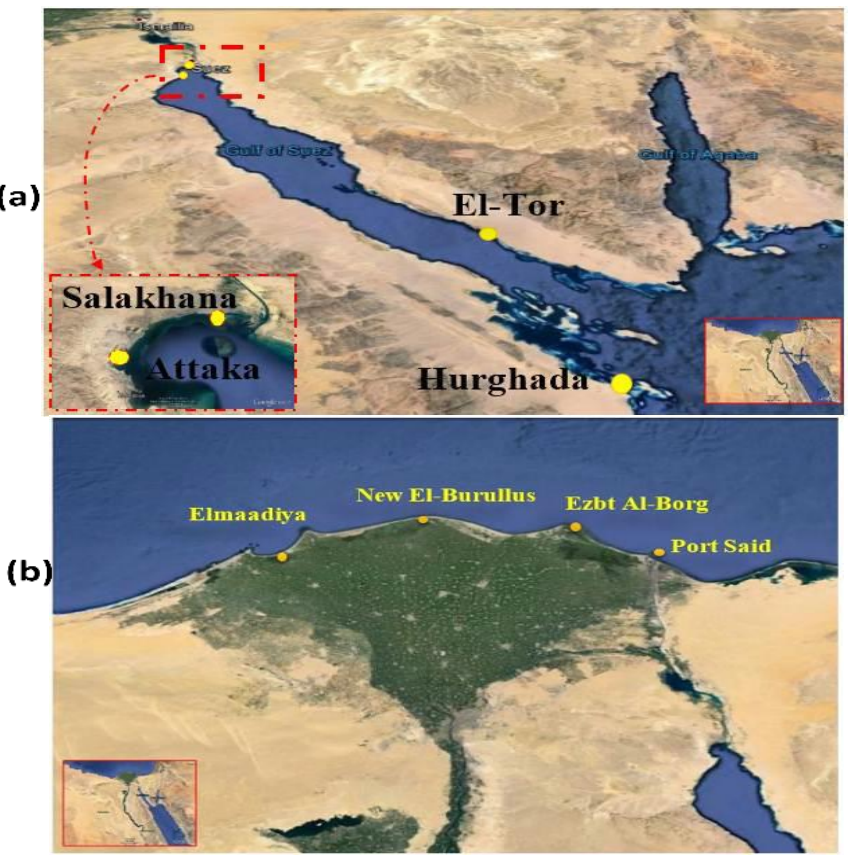

Figure 3: Fishery ports along Egyptian coasts; (a) Red Sea Egyptian coast, and (b) Mediterranean Sea Egyptian coast. [19]

The model set with $100 \%$ of tracer material concentration as an initial condition for all simulations.
The time step is taken 0.5 hour (30minutes) and, therefore, the model is converged for each time step.

\subsection{Water Level Variations Data}

In order to simulate the water flow movement through tidal inlets, it is necessary to have data of time varying water level variation at the open seaward boundary. It is common, in previous research such as (Falconer, [7]), to use average records that represent the tidal zone. It is recommended by DHI [5] that if the study is for specific area, it is preferred to use the available records or tidal predictor software.

Therefore, in this study, a wide range of water levels variations are applied in different scenarios based on the recorded tidal levels in the above-mentioned coastal zones. This range is varied from $0.5 \mathrm{~m}$ to $4.0 \mathrm{~m}$ as shown in Figure 4. The water level variation forms a sinusoidal shape that repeated twice per day. This process produces the current of ebb and flood each $6.25 \mathrm{hr}$. The applied criteria of water level variation values as boundary conditions in the model setup is presented in Figure 4. The importance of studying such parameter is that the current speed and direction produced during ebb and flood are dominated by inlet characteristics (width, location, and numbers) and water level variation values along the tidal cycle.

According to water level variations, it reaches to a maximum value in case of $4 \mathrm{~m}$ variation between the high and low water levels and decreased gradually to reach a minimum value in case of 0.5 (ATT, [1]).

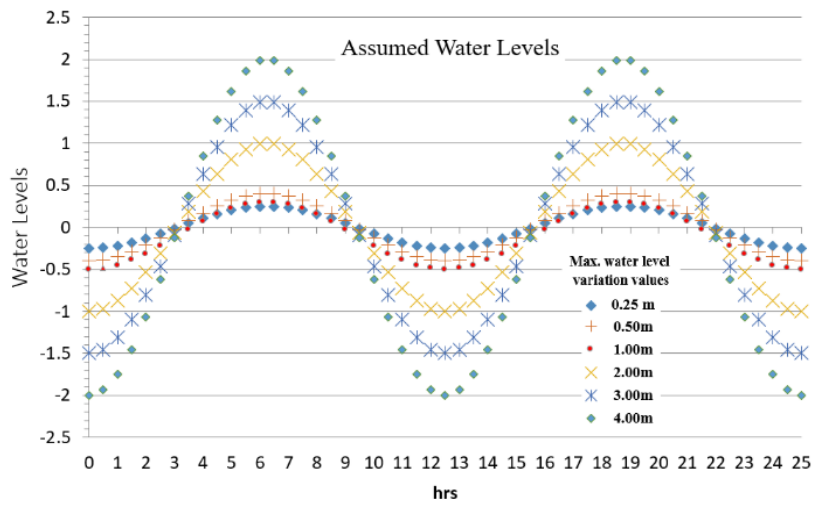

Figure 4: Applied water level variations values.

\subsection{Water Depth}

In the coastal zone of the study interest, the lagoons are generally shallow with depths vary from $0.5 \mathrm{~m}$ to $2.5 \mathrm{~m}$, but in marinas and fishery ports it becomes deeper and may reach to $6.0 \mathrm{~m}$. In this study, the semi-closed water body is given a uniform depth with 5 different values vary from 0.5 $\mathrm{m}$ to $4.0 \mathrm{~m}$ below the lowest tidal water level represents a geometry parameter of the semi-closed water body.

\subsection{Geometry of the Water Body}

The representation of the semi-closed water body's geometry has been assumed based on desk study of Egyptian marinas and coastal lagoons. This representation leads to a semi-closed rectangular water body with a uniform depth through the following parameter: 

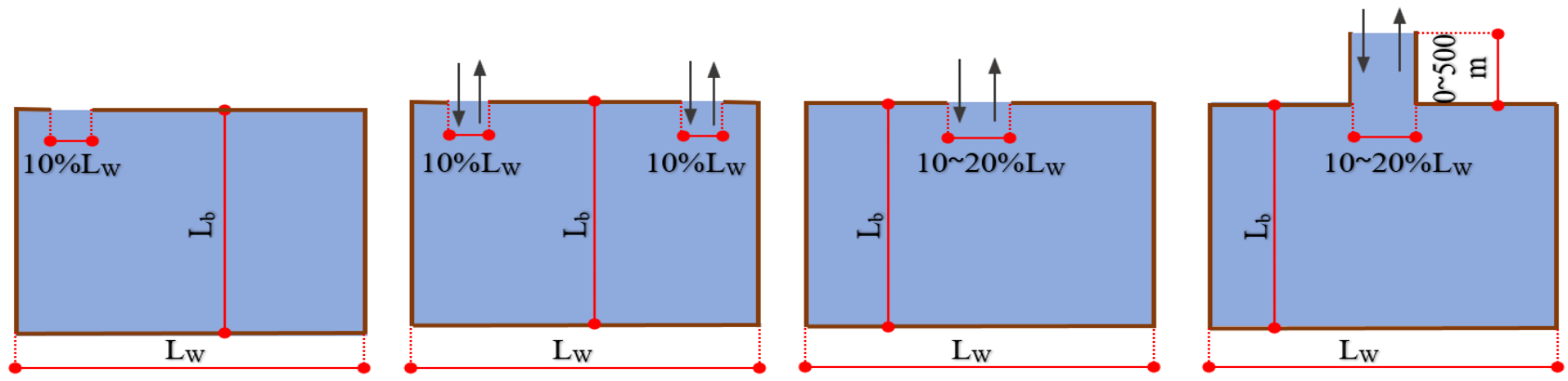

Figure 5: Geometry of different scenarios for simulated water body

\section{(a) Water surface area}

Based on the dimensions of water surface area in marinas and coastal lagoons along Egypt coasts, it is clear that they have a wide range of water surface areas. Accordingly, this study deals with many different cases to cover this range as shown in Figure 5.

(b) Tidal inlets (number, width, and location)

Generally, most of lagoons and ports have one or two entrance which is defined as the gate of water change between the inside water body with the open sea water. The models were built with one and two inlets in different locations with variable width varied from $10 \%$ up to $25 \%$ of basin width $\left(\mathrm{L}_{\mathrm{w}}\right)$ as shown in Figure 5. The

model shown in Figure 5 which simulated with one middle inlet at (width $=10 \% \mathrm{~L}_{\mathrm{w}}$ ) is called $\mathrm{R} 1$, while the model simulated with one middle inlet at (width $=20 \% \mathrm{~L}_{\mathrm{w}}$ ) is called R2. The model which simulated with one side inlet at (width $=10 \% \mathrm{~L}_{\mathrm{w}}$ ) is called R3, and finally the model simulated with two side inlets at (width $=10 \% \mathrm{~L}_{\mathrm{w}}$ ) is called $\mathrm{R} 4$. The calculated results of numerical simulations are plotted as blue dotes over the graph given by Falconer, [8] as presented in the left side of Figure 6.

(c) Entrance channel

The length of entrance channel has a significant effect on the current velocities, directions, and water volume entering the water body. Thus, the model scenarios were carried out with three different channel lengths starting from zero to 500 $\mathrm{m}$ as shown in Figure 5.

(d) Length to width ratio $\left(\mathrm{L}_{\mathrm{w}} / \mathrm{L}_{\mathrm{b}}\right)$

Ports always consist of numbers of basins with rectangular or square shapes with variable length $L_{w}$ to width $L_{b}$.

In this study, a number of different length-towidth ratios $\left(\mathrm{L}_{\mathrm{w}} / \mathrm{L}_{\mathrm{b}}\right) \quad$ were used in the model setup ranging from 0.25 to 4.0 .

\subsection{Model Calibration}

In order to check the capability of the model, a comparison was conducted with the results presented on Coastal Engineering Manual (Demirbilek, and Vincent [2]). The results were obtained by extensive physical and numerical modelling of various cases which studied the relation between the exchange coefficient and water body length to width ratio $\left(L_{w} / L_{b}\right)$, Which was simulated by similar Simi closed water body geometry. Therefore, the exchange coefficient $(E)$ was simulated to obtain the exchange coefficient values for water exchange during each tidal cycle. The average per cycle exchange coefficient $(E)$ is given by Nece, and Richey, [16] as:

$$
E=1-\left(\frac{C_{i}}{C_{0}}\right)^{\frac{1}{i}}
$$

Where, $C_{0}$ is the initial concentration of substance in water body and $C_{i}$ is the concentration of this substance after $i$ tidal cycles. Figure 6 shows the comparison between the physical models' results that were carried out in 1980 by Falconer for a semi-closed water body. These models simulated by rectangular water surface geometry with one side inlet as shown in Figure 6 (b) and were conducted with varied aspect ratio $\left(\mathrm{L}_{\mathrm{w}} / \mathrm{L}_{\mathrm{b}}\right)$ at constant tidal prism ratio $T P R$ $=0.4$ in order to be matching with the physical model which carried out by (Falconer,[8]). The calculated results of numerical models are plotted as blue dotes over the graph given by Falconer, [8] as shown in Figure 6 (a). In general, the results of calibration show a high level of accuracy.
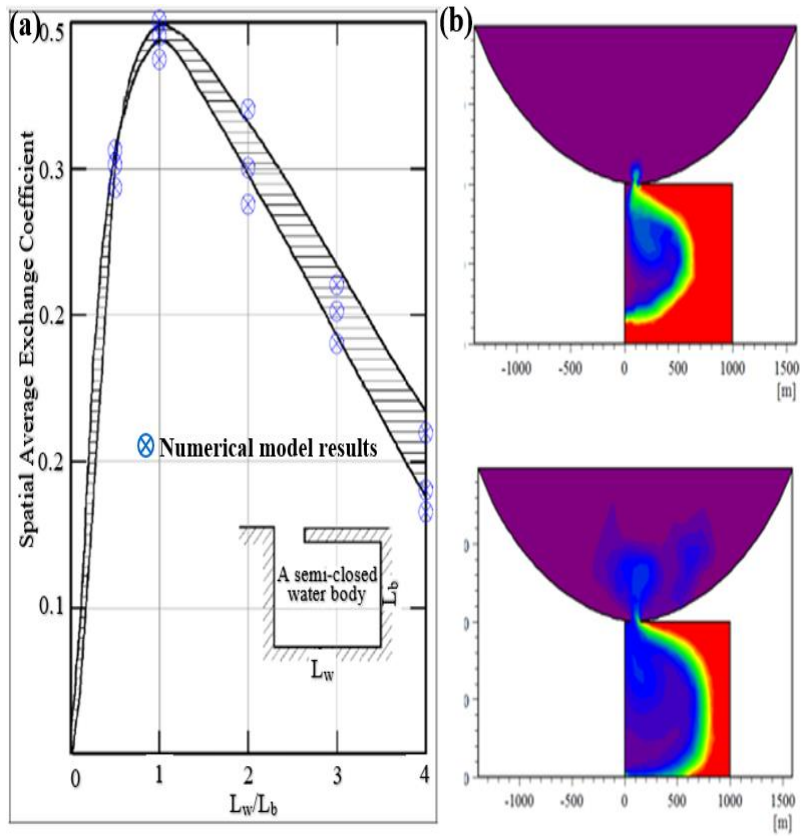

Source, $[8]$ 


\section{METHODOLOGY}

In this study, a wide range of numerical simulations (more than 50 HD models) with different geometry and boundary conditions were conducted. The simulated scenarios can be categorized as followed:

(a) Type A: a square waterbody (i.e. $L_{w}=L_{b}$ ) with variable water surface areas and different inlets alignment, numbers, and width. In this type, 12 scenarios were simulated with different criteria as shown in Figure 7.

(b) Type B: a rectangular waterbody with variable $\left(\mathrm{L}_{\mathrm{w}}\right.$ $/ \mathrm{L}_{\mathrm{b}}$ ) ratio at constant tidal prism ratio (i.e. tide value to depth is constant) equal 0.4. Also, it was simulated for different inlet characteristics similar to the previous type. In this type, 12 scenarios were simulated with different criteria as shown in Figure 8.

(c) Type $C$ : a square waterbody (i.e. $L_{w}=L_{b}$ ) with constant surface area and one middle inlet. This type was conducted under variable water level, depth, and entrance channel length. In this type, 21 scenarios were simulated with different criteria as shown in Figure 9.

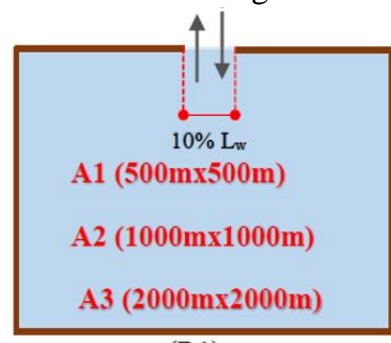

(R1)

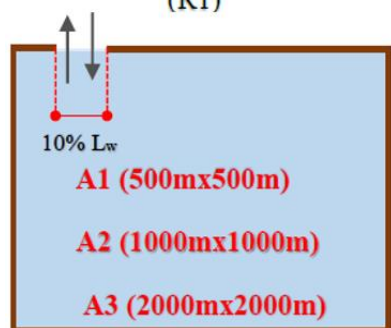

(R3)
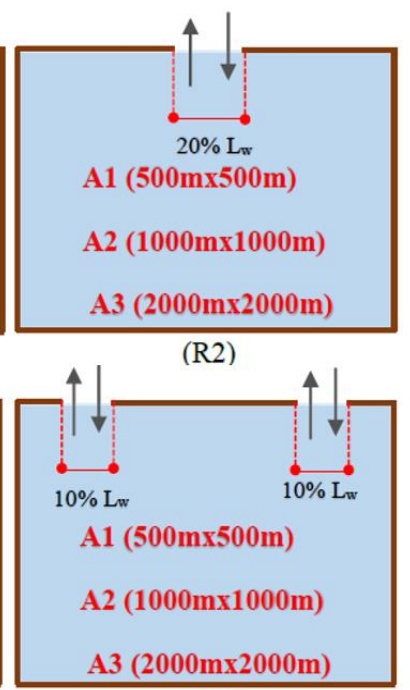

(R4)

Figure 7: Type $(A)$ simulation scenarios

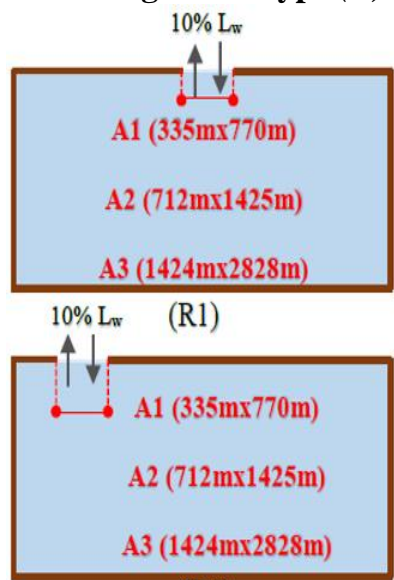

(R3)

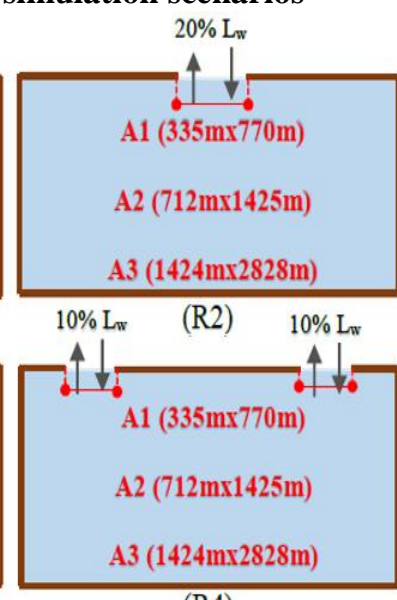

(R4)

Figure 8: Type $(B)$ simulation scenarios
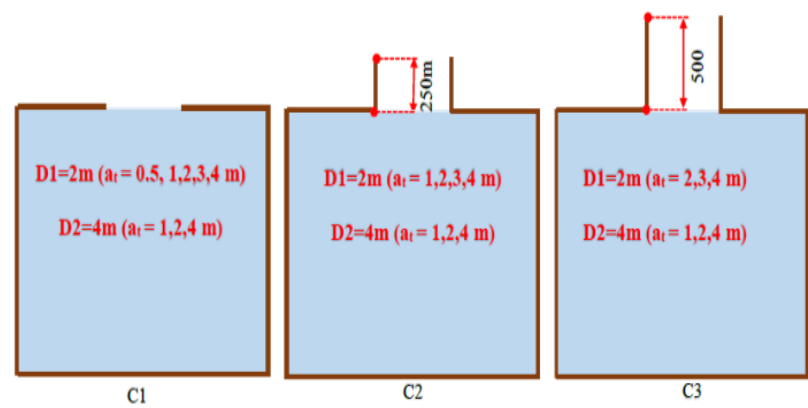

Figure 9: Type $(C)$ simulation scenarios

\section{RESULTS AND DISCUSSION}

The results of all simulation scenarios were presented in the form of plans and profiles for 9 selected points almost cover the water body as shown in Figure 10. The presented plans supported by grading color maps represent currents and tracer concentration percentage. While, the vectors describe the current directions on plan to understand the flow motion. The 9 selected points present the values of tracer concentration percentage and current velocities at its location in profile shape with 0.50 hour time step along simulation run time. The following sections will discuss the effect of different parameters on water flushing according to results of relevant scenarios.

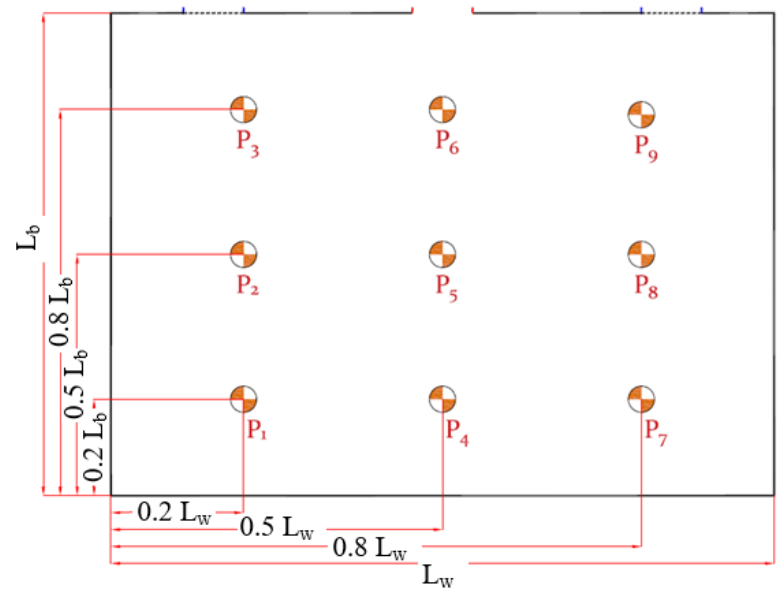

Figure 10: Location of selected Presentation points

\subsection{Effect of Water Surface Area and Geometry}

In type $(A)$ simulation scenarios, the results show that the average flushing time to decrease average tracer concentration to less than $20 \%$ are 37,96 , and 270 hours for the case of water areas $A 1(500 \mathrm{~m} \times 500 \mathrm{~m}), A 2(1000$ $\mathrm{m} \times 1000 \mathrm{~m})$, and $A 3(2000 \mathrm{~m} \times 2000 \mathrm{~m})$, respectively. The tracer concentration for $A 1$ and $A 3$ are shown in Figures 11 and 12 after 50 hours and 280 hours, respectively.

Based on the results of type $(A)$, it is shown clearly that when the water surface area $(A)$ increased by 4 times, the needed flushing time to reach the same average tracer concentration percentage $\left(T_{f}\right)$ will increase by 2.8 times, approximately.

In case of rectangular shape type $(B)$ with $\left(\mathrm{L}_{\mathrm{w}} / \mathrm{L}_{\mathrm{b}}=2\right)$, the results show that the average flushing time to decrease the average tracer concentration to be less than $20 \%$ is 75 , 
120,260 hours for the case of water areas $A 1(770 \mathrm{~m} \times 335$ $\mathrm{m}), A 2(1425 \mathrm{~m} \times 712 \mathrm{~m})$, and $A 3(2828 \mathrm{~m} \times 1424 \mathrm{~m})$, respectively. Therefore, the results show that when the water surface area increased 4 times in rectangular shape, the needed flushing time to reach the same average tracer concentration percentage will increase by 1.7 times approximately.

The differences in results between type $(A)$ and type $(B)$, concerning water surface area and its effect on flushing time, mean that the higher ratio of $\left(L_{w} / L_{b}\right)$ the lower effect on flushing time. Furthermore, it is also concluded that the flow can reach easily to the furthest point in basin (along the side length $L_{b}$ ) when $L_{b}$ is shorter than the side length $L_{w}$, but, similarly, the spreading horizontally will also be decreased. In general, the effect of the square shape on the flushing time is better than the rectangular shape. However, this difference in effect is decreased by increasing the water surface area especially in the case of two inlets.

Figure 13 shows examples of the tracer concentration for the selected corner points 3 and 7 for scenario A1. Figure 14 shows the tracer concentration for the same points location points 3 and 7 for scenario $A 2$.

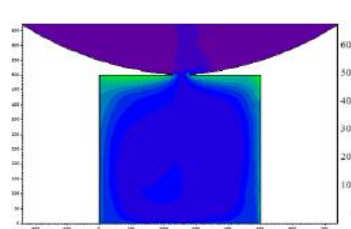

$\overrightarrow{\mathrm{R}} 1$

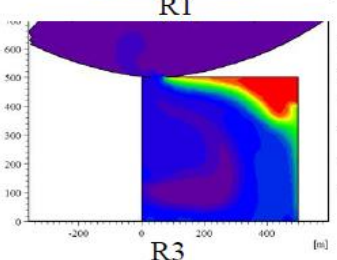

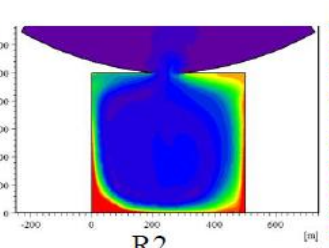

R2

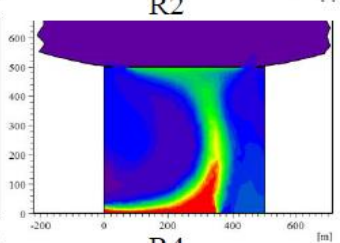

$\mathrm{R} 4$

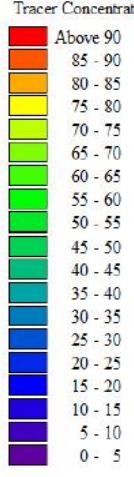

Figure 11: Tracer Concentration for Type (A) Scenario A1 (500 m x $500 \mathrm{~m})$ after $50 \mathrm{hrs}$.
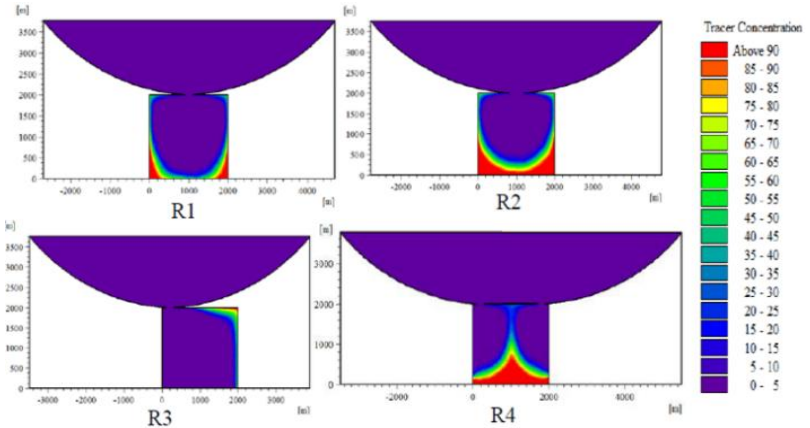

Figure 12: Tracer concentration for Type (A) Scenario A3 (2000 m x $2000 \mathrm{~m})$ after 280hrs.

The results show that when increasing the area, there is no significant change in flow spreading in the direction parallel to the inlet width, but it decreases in the direction perpendicular to the inlet width. This is clearly deducted by comparing between the nearest points to the inlet $(3,6$, and 9) and the furthest points (1, 4, and 7) in the two scenarios $A 1$, and $A 2$. The average time to reduce average tracer concentration percentage less than $20 \%\left(\mathrm{~T}_{\mathrm{f}} 20 \%\right)$ at these points are presented in table 1 in hours (hrs.).
Table 1: Average flushing time $\left(\mathbf{T}_{\mathrm{f}} 20 \%\right)$ at points $(3,6,9,1,4$, and7) for scenarios $A 1$ and $A 2$

\begin{tabular}{|l|c|c|}
\hline Points & $\mathrm{T}_{\mathrm{f} 20 \%}-$ Scenario $\mathrm{A} 1$ & $\mathrm{~T}_{\mathrm{f} 20 \%}$ - Scenario A2 \\
\hline Point 3 & $25 \mathrm{hrs}$. & $30 \mathrm{hrs}$. \\
\hline Point 6 & $45 \mathrm{hrs}$. & $65 \mathrm{hrs}$. \\
\hline Point 9 & $85 \mathrm{hrs}$. & $85 \mathrm{hrs}$. \\
\hline Point 1 & $40 \mathrm{hrs}$. & $100 \mathrm{hrs}$. \\
\hline Point 4 & $50 \mathrm{hrs}$. & $200 \mathrm{hrs}$. \\
\hline Point 7 & $35 \mathrm{hrs}$. & $120 \mathrm{hrs}$. \\
\hline
\end{tabular}

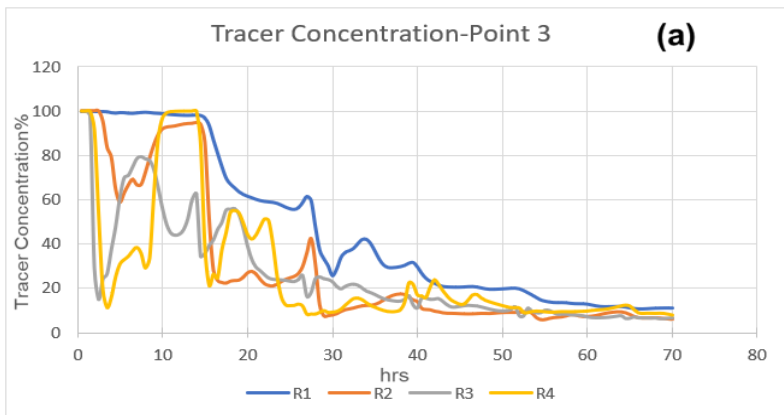

Tracer Concentration-Point 7

(b)

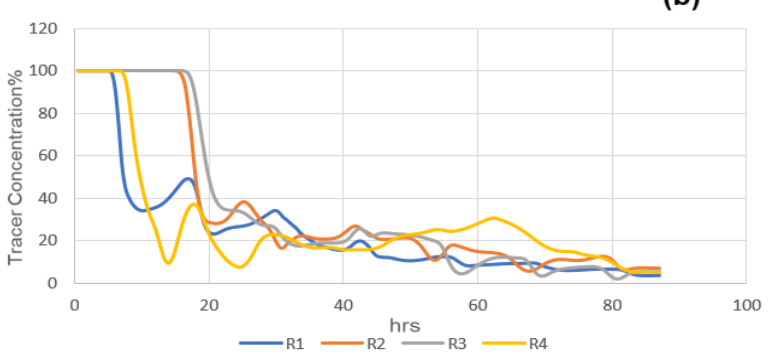

Figure 13: Tracer conce ntration for scenario A1: (a) points 3, and (b) point 7

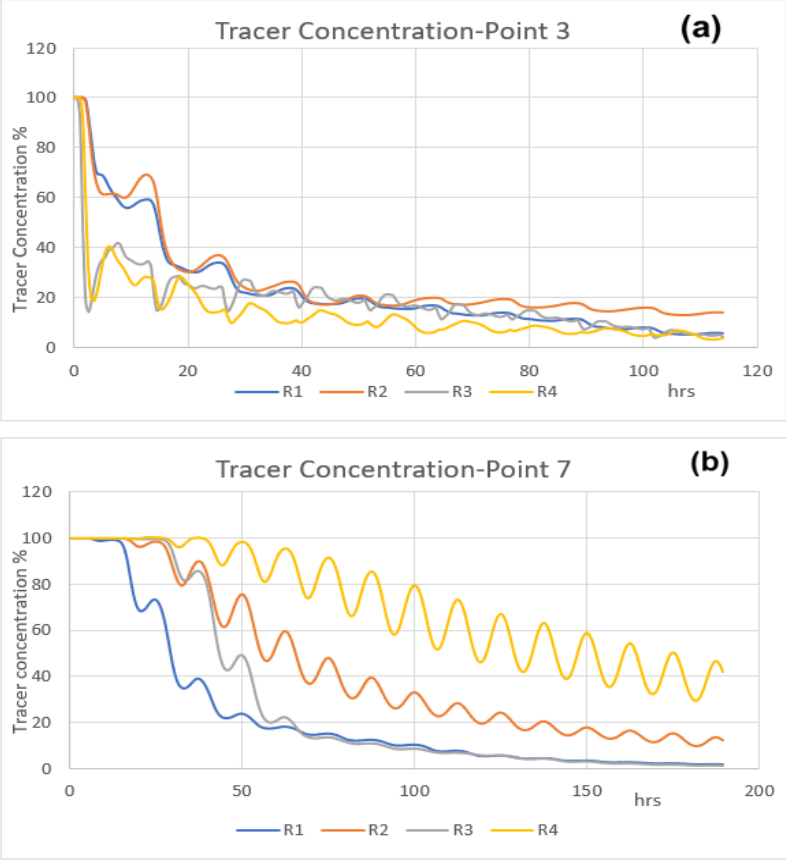

Figure 14: Tracer concentration for scenario A2: (a) points 3, and (b) point 7 


\subsection{Effect of Inlet Width}

As described before in section 3 , the effect of the inlet width and its location were conducted at three different locations with variable inlet width ratio relative to the basin width ranged from $10 \%$ to $20 \%$ of $\mathrm{L}_{\mathrm{w}}$. The results show that the inlet width has a great effect on both the water volume entering the semi-closed water body during flood and the current velocities that dominate the dispersion and flow spreading process.

By comparing between the results of the average tracer concentration of water surface area resulted from the two scenarios R1 and R2 presented in Figure 11 and 12, the results show that the water flushed faster in case of $\mathrm{R} 1$ (with inlet width $=10 \% L_{w}$ ) than in case of R2 (with inlet width $=20 \% L_{w}$ ).

These results indicate that both of the water level variations and water levels of Egyptian coasts used in this study are relatively insufficient to produce current velocity required to spread water flow and reach to the furthest zones of the basin especially in the case with inlet width of $20 \% L_{w}$. While, in the case of inlet width of $10 \% L_{w}$, the current velocity increased and able to spread in better way to flush the basin water faster. The current velocity and direction in the two cases are shown in Figure 15 which assure and illustrate the effect of inlet width on current velocity and flow spreading quality inside the basin. The results show that the current velocity in $\mathrm{R} 1$ scenario is much higher, almost double, than R2 scenario.

Therefore, it is concluded that the inlet width controls the quantity of water volume entering the basin and its efficiency of spreading to cover surface water body area. Also, it is clear that there is a strong relation between inlet width and water level variation. In order to achieve best flushing results, the planners and designers shall determine the minimum velocity that able to reach the furthest area of basin and it will guide for the large possible inlet width. This criterion will allow the largest possible amount of open sea water volume to enter. In other words, it is important to connect between the minimum velocity required to reach the furthest zones of the basin and the possible inlet width that allow the maximum quantity of freshwater volume to enter the basin.

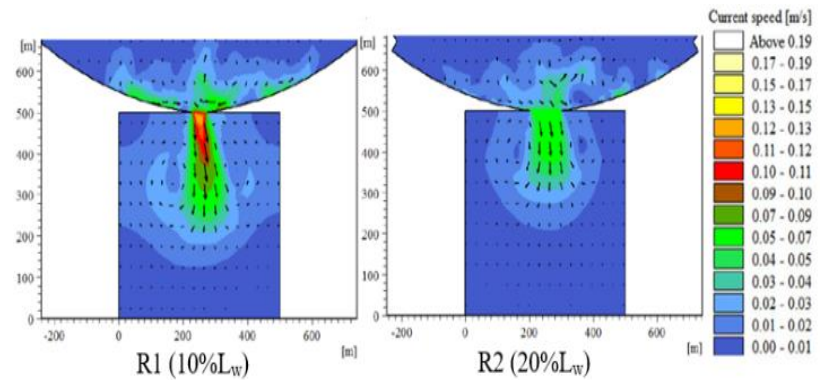

Figure 15: Current velocity and directions in case of $10 \% L_{w}$ and $20 \% L_{w}$ inlet width scenario

\subsection{Effect of Inlet Location and Numbers}

Generally, the inlet location determines which zone inside the basin will be flushed before the others. In the same way, by understanding the effect of inlets location, it is possible to prevent the existence of the stagnant areas or, at least, expect where it could be located.
Figure 16 shows that despite of the middle inlet in R1scenario in type $A$ produce best average flushing time, point 9 flushed faster in case of using 2 side inlets in R4 scenario. On the contrary, both points 4 and 5 need very long time to be flushed in case of using two side inlets in R4 scenario compared with the other scenarios as shown in figure 17.

In section 4.1, the results prove that square shape produce better flushing efficiency in general specially in case of one side inlet due to the long distance between other side points to the inlet that need high velocity to be flushed. Figure 18 shows that, in both types (A) and (B), point 9 takes the longest time in R3-case to be flushed with high difference compared to the other points. In type $b$, it is not only point 9 takes the longest time but also point 8 and 7.The result shows that, in small water surface areas, the best inlet alignment is to be in the middle, while the worst inlet alignment is to be in one side inlet where the furthest corner zone takes the longest time to be flushed.

Based on the presented results, in the case of areas larger than $4 \mathrm{Km}^{2}$, the use of two side inlets becomes better alignment than one in the middle, but it should be located to make the water surface acts as two square shape to optimize flushing process. In conclusion, the optimum inlets number and location generally depends on water surface geometry (shape, water surface area, $\mathrm{L}_{\mathrm{w}} / \mathrm{L}_{\mathrm{b}}$ ratio), and sometimes depends also on the purpose of this basin water area.

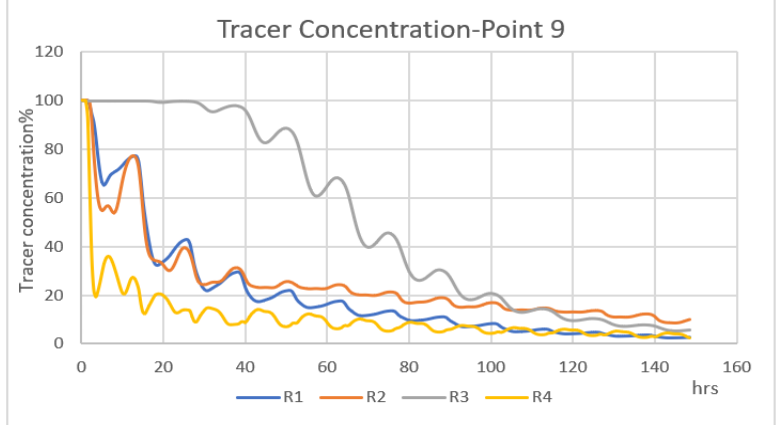

Figure 16: Tracer concentration at point 9 for scenario A2

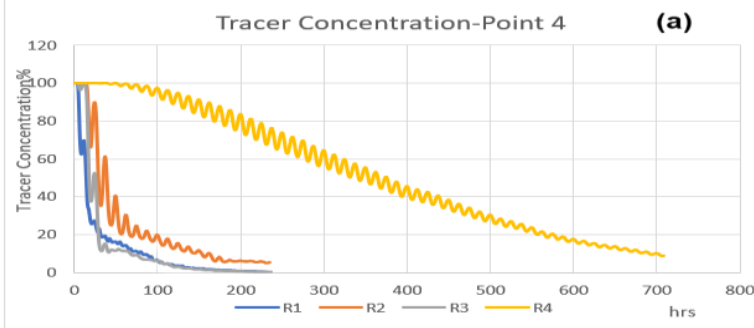

Tracer Concentration-Point 5

(b)

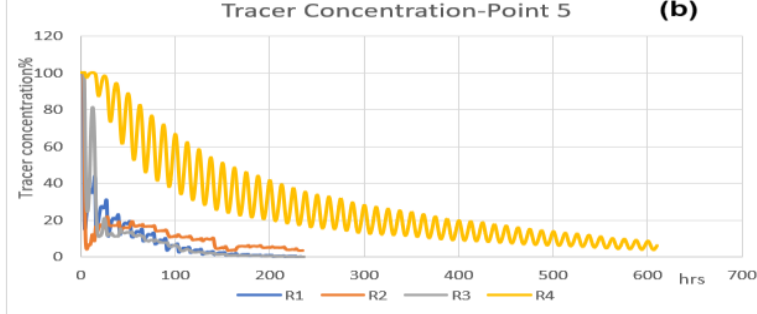

Figure 17: Tracer concentration for scenario A2: (a) points 4, and (b) point 5 

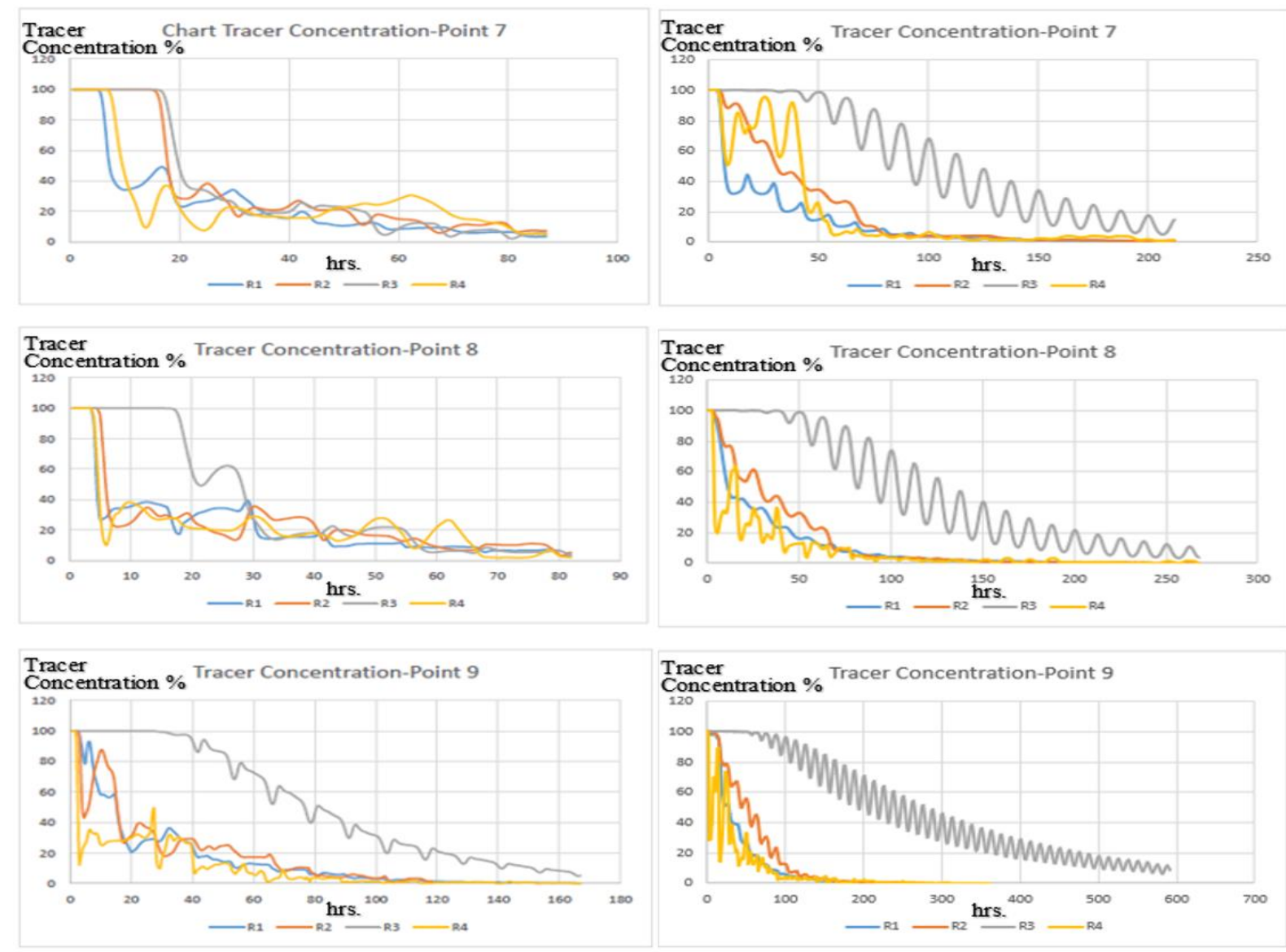

(Type $A$ )

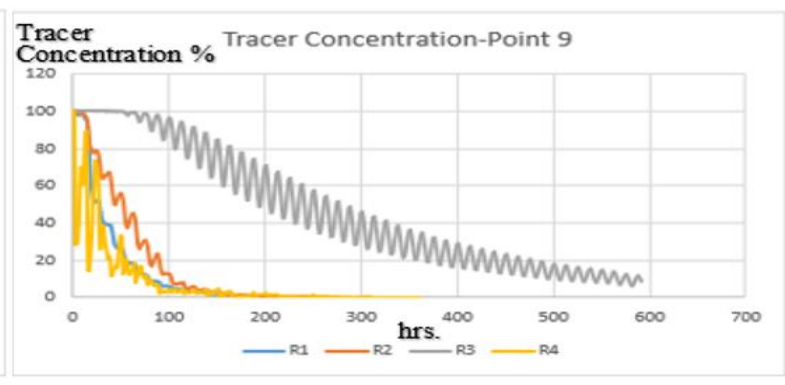

(Type B)

Figure 18: Comparison between flushing result at side Points type $(A)$ and type $(B)$ scenarios

\subsection{Effect of Water Level Variation}

The study shows that there is a strong relation between water level variation values and inlet width, where water level variation controls the values of current velocities at the inlet. In other words, the higher values of water level variation, the widest inlet we can use. In case of low-water level variations, a small inlet width should be used to achieve the desired current velocity that able to deliver fresh water to the furthest corners within the water body area. In contrast, the high-water level variation values able to produce the desired current velocity even with large inlet width.

In order to understand the effect of water level variations on both the current velocity and flushing efficiency, a several number of simulated scenarios have been considered. They are conducted at the same conditions such as; surface area, water depth, and inlet characteristics, but with different values of water level variation as described in Figure 9.

Figure 19 shows a sample of these kind of results. It describes the plan of current velocities in C1-D1 scenario with two different values of water level variation values 0.5 $\mathrm{m}$ and $4.0 \mathrm{~m}$, respectively. The results indicated that the maximum flood current velocities calculated at the entrance in both scenarios of water level variation values are $0.12 \mathrm{~m} / \mathrm{s}$ and $0.65 \mathrm{~m} / \mathrm{s}$, respectively. While, the maximum flood current velocities at the entrance in other cases of water level variations values $(1.0 \mathrm{~m}, 2.0 \mathrm{~m}$, and $3.0 \mathrm{~m}$ ) are $0.32 \mathrm{~m} / \mathrm{s}, 0.45 \mathrm{~m} / \mathrm{s}$, and $0.55 \mathrm{~m} / \mathrm{s}$, respectively.
These results indicate that, at constant water depth, as the level variations values increased, the maximum flood current velocities at the entrance increased.
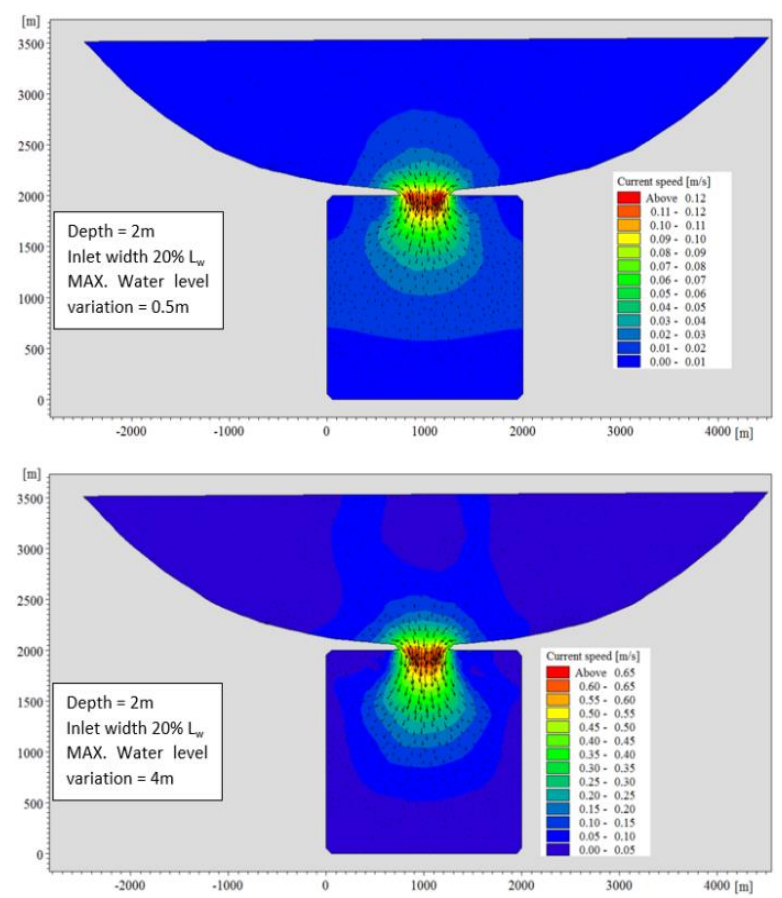

Figure 19: Current velocity comparison between two different water level variation $0.5 \mathrm{~m}$ and $4 \mathrm{~m}$ 
In general, the flow is spreading widely with the higher water level variation values over the all water surface area regardless the water depth. Figure 20 and 21 show the results of the tracer concentration percentage at the selected points for two scenarios at constant depth to water level variation ratio.
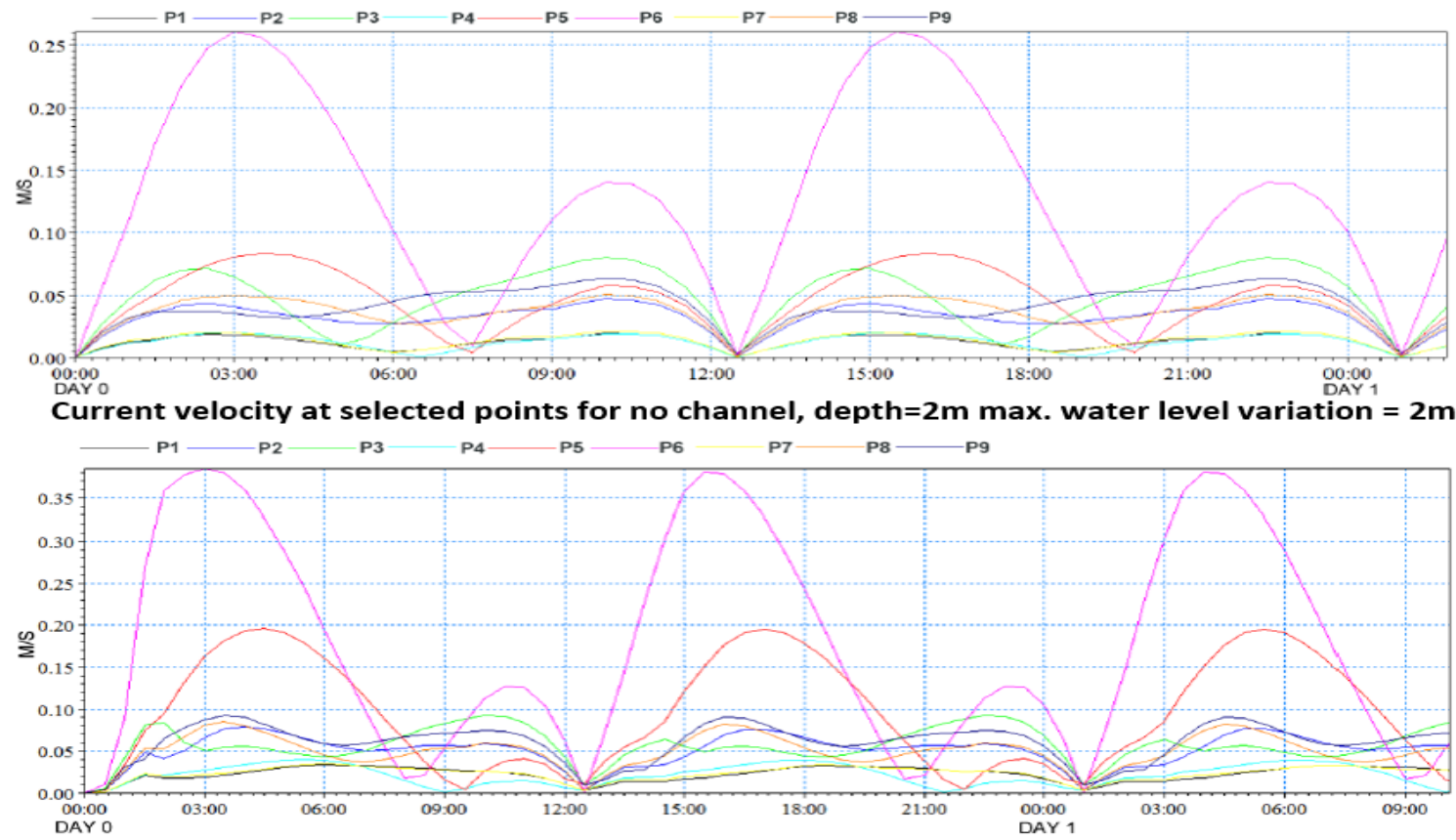

Current velocity at selected points for no channel, depth $=4 \mathrm{~m}$ max. water level variation $=4 \mathrm{~m}$

Figure 20: Current velocity at selected points for two scenarios with constant depth to water level variation ratio.

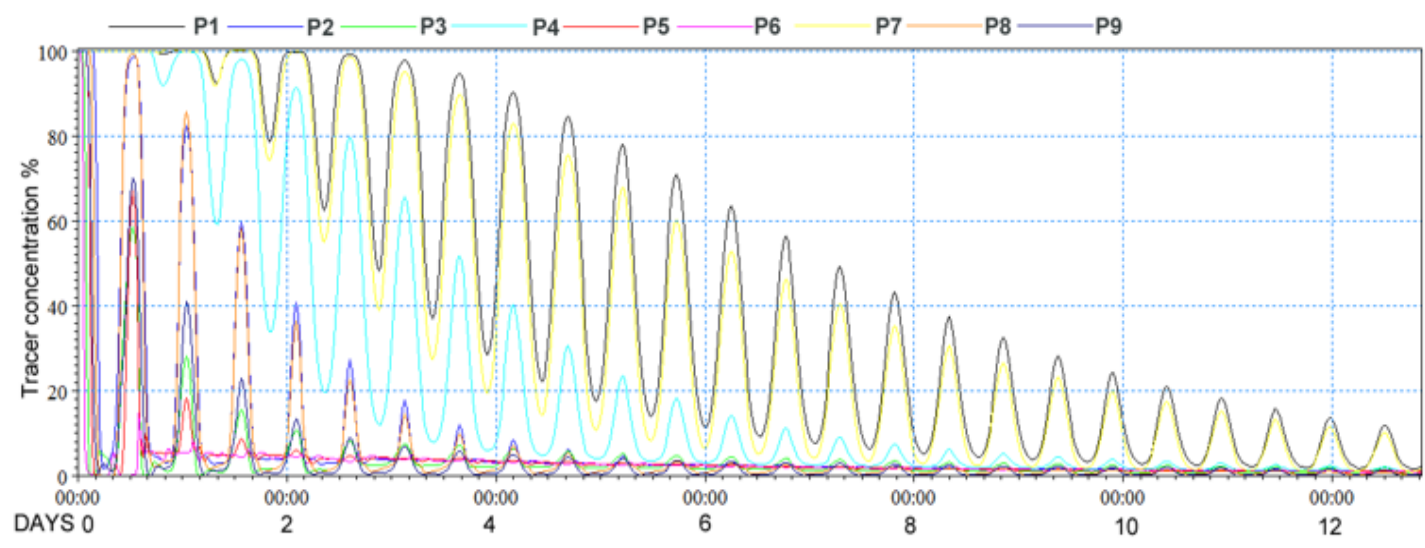

Tracer Concentration $\%$ at selected points for no channel, depth=2m max. water level variation $=\mathbf{2 m}$

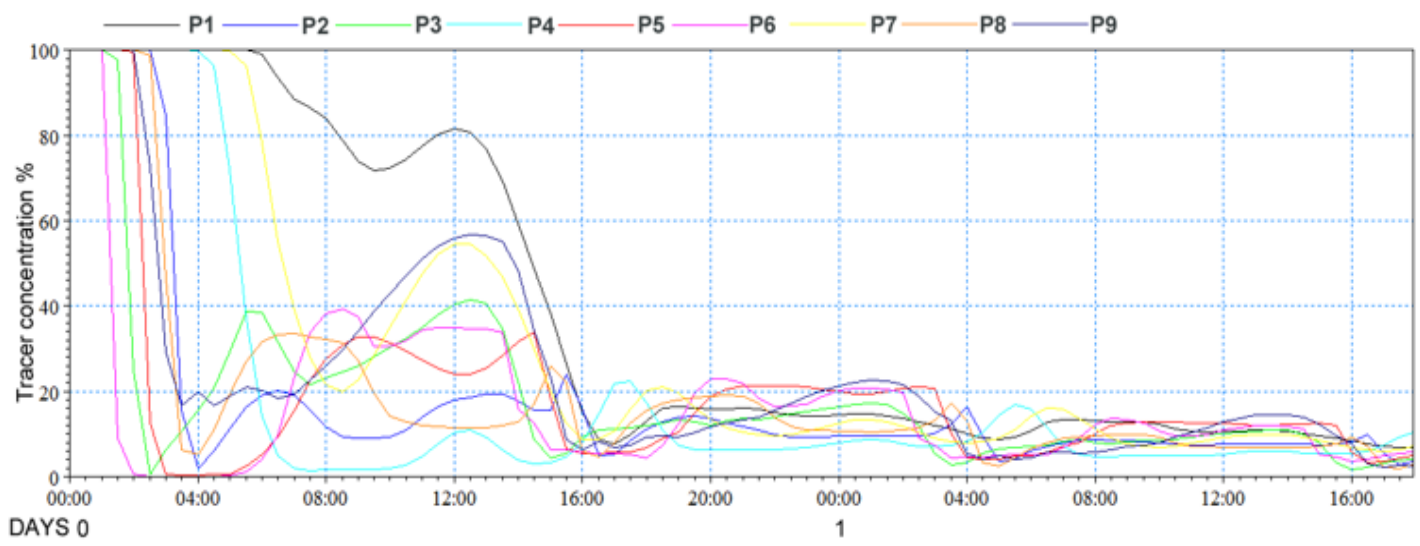

Tracer Concentration $\%$ at selected points for no channel, depth $=4 \mathrm{~m}$ max. water level variation $=4 \mathrm{~m}$

Figure 21: Tracer concentration at selected Points for two scenarios with constant depth to water level variation ratio 
The first scenario is simulated at a water depth $=2.0 \mathrm{~m}$ and water level variation value $=2.0 \mathrm{~m}$, while the other scenario is simulated at when $=4.0 \mathrm{~m}$ and water level variation value $=4.0 \mathrm{~m}$. These results clearly assure that flow is spreading widely with the higher water level variation values over the all water surface area regardless the water depth. In other words, it means that the average current value, in case of high-water level variation, near water surface will always be higher than the correspondence values in case of the lower water level variation values regardless the water depth.

\section{CONCLUSION AND RECOMMENDATIONS}

- The study proves the importance of studying the flushing characteristics for coastal projects, marina, and lagoons development. Also, the planning of these projects should consider the nature condition of project area (Tidal levels, location, Wave, Wind, Marine biology, future planning, etc.)

- In planning of port, marinas, and lagoons, the basin aspect ratio $L_{w} / L_{b}$ should be greater than 0.33 and not exceed 3. In general, it is preferable to be from 0.5 to 2.0 .

- The study presents a way to represent a general prediction for the expected flushing time of a specific semi-closed water surface area by determining flushing time of another water surface area with square or rectangular geometry. In small semi-closed water surface area planning, it is recommended to use the square shape which considered more efficient especially with one middle inlet. In case of larger semiclosed water surface area more than $4 \mathrm{~km}^{2}$, it is recommended to use the rectangular geometry shape with two side inlets in order to acts like two square geometry.

- The inlet width and its location should be determined wisely to achieve the optimization for the usage of project. The inlet width depends on the water level variation values in the project area where larger width used in coastal area with larger water level variation in order to produce the desired current speed which able to reach the furthest corners of water basin and largest freshwater volume could be entered. The inlet location shall be selected based on the predicted stagnate area.

- The objective of the coastal planning is to improve the water quality inside the semi-closed marinas and coastal lagoon by allowing the largest possible volume of water to enter and also reach to the furthest zones. In That way, this large amount generally needs a wider inlet width, while to reach the open sea water to the furthest zones, it needs a narrow inlet width to produce high velocity. Therefore, the planner shall optimize the designed inlet width based on the tidal zone of project to achieve the desired current velocity with the largest volume of water. Finally, as the water level variations in Egyptian coasts is relatively small, it is recommended that the inlet width should be equal to 10 to 20 percent of the semi-closed basin width.

\section{Credit Authorship Contribution Statement:}

Elsayed M. Galal: Visualization, conceptualization, Methodology, Original draft preparation, Supervision, editing, and reviewing. Ahmed A. Lebleb: Literature review, Methodology, Software, Formal analysis, Original draft preparation; and Investigation; Ehab R. Tolb: Visualization, supervision, Investigation, and reviewing.

\section{DECLARATION OF COMPETING INTEREST}

The authors declare that they have no known competing financial interests or personal relationships that could have appeared to influence the work reported in this paper.

\section{REFERENCES}

[1] ATT, Admiralty Tide Tables, Volume 1, (NP201), United Kingdom Hydrographic Office, 2016.

[2] Z., Demirbilek, and L. Vincent, "Water Wave Mechanics Chapter, II: Coastal Engineering Manual, EM 1110-2-1100, Part II, Chapter 7 (HARBOR Hydrodynamics, U.S. Army Corps of Engineers, Washington, DC, 2008.

[3] DHI, "MIKE 21 \& MIKE 3 Flow Model FM Hydrodynamic Module Short Description", Danish Hydraulic Institute, 2015.

[4] DHI, "MIKE 21 Flow Model FM Hydrodynamic Module user Guide", Danish Hydraulic Institute, 2011.

[5] DHI, "MIKE 21 Tide Analysis and Prediction Module - Scientific Documentation. Danish Hydraulic Institute, 2017.

[6] P.P., Dyke, "Modeling Coastal and Offshore Processes", Imperial College Press, 2007.

[7] R.A., Falconer, "A mathematical model study of the flushing characteristics of a shallow tidal bay", Proceedings of the Institution of Civil Engineers, EISSN 1753-7789, Volume 77 (3), pp. 311-322, 1984.

[8] R.A., Falconer, "Modelling of Planform Influence on Circulation in Harbors," Proceedings, 17th International Conference on Coastal Engineering, American Society of Civil Engineers, pp 27262744,1980.

[9] C.K., Goshow, S.E., Hosseini, and S., O’Neil, "Waterfront Developments in the Gulf Region: A Review and Examination of Flushing and Its Relevance to Water Quality", 7th International Conference on Coastal and Port Engineering in Developing Countries, (COPEDEC VII), Dubai, Paper No. 59, 2008.

[10] J.A., Simmons, M.D., Harley, L.A., Marshall, I.L., T urner, K.D., Splinter, and R.J. Cox, "Calibrating and assessing uncertainty in coastal numerical models," Coastal Engineering Journal 125:28-41, 2017.

[11] J., Juhl, and T., Gierlevsen, "Marine Land Development in Qatar", COPEDEC VII, Dubai, UAE, 2008.

[12] R., Klein, "Hydrodynamic Simulation with MIKE21 of Mele Bay and Port Vila, Vanuatu". SOPAC Technical Report 263. Nabua, Suva, Vanuatu, 1998.

[13] M.J., Blacka, J.T., Carley, R.J., Cox, and B.M., Miller, "The Current use of Physical and Numerical Models for Coastal Applications", University of New South Wales Coastal Conference, 2007.

[14] M.J., Miller, J.L., Pietrafesa, and N.P., Smith, "Principles of hydraulic management of coastal 
lagoons for aquaculture and fisheries", FAO Fisheries Technical Paper, No. 314, 1990.

[15] N. E., Nece, "Planform Effects on Tidal Flushing of Marinas".J. Waterway, Port, Coastal and Ocean Eng. Div., A.S.C.E., pp.251-269. 1984.

[16] R.E., Nece, and E.P., Richey, "Flushing Characteristics of Small Boat Marinas." Proc. Thirteenth Coastal Engineering Conference, Vancouver, B.C., Vol. III, 1972.

[17] P.C., Kusnierz, H.I., Jager, and A.S., Todd, “A Call for Collaboration among Water Quality and Fisheries Professionals, Fisheries, 2019.

[18] R., Ranasinghe and C., Pattiaratchi, "Flushing characteristics of seasonally open tidal inlet: A Numerical study", Journal of coastal research, 14(4),1405-1421, Royal palm beach (Florida, ISSN 0749-0208, 1998.

[19] M., Sharaan, A., Negm, M., Iskander, and K., Nadaoka, Questionnaire-based assessment of Mediterranean fishing ports, Nile Delta, Egypt. Marine Policy, 81, pp.98-108, 2017.

[20] R.V., Thomann, and J.A., Mueller, "Principles of Surface Water Quality Modeling and Control”, HarperCollins, New York, 1987. 